\title{
Multiobjective Optimization Based Vessel Collision Avoidance Strategy Optimization
}

\author{
Qingyang Xu, ${ }^{1}$ Chuang Zhang, ${ }^{2}$ and Ning Wang ${ }^{2}$ \\ ${ }^{1}$ Shandong University, Weihai, China \\ ${ }^{2}$ Dalian Maritime University, Dalian, China \\ Correspondence should be addressed to Qingyang Xu; xuqy1981@163.com
}

Received 9 November 2013; Revised 23 December 2013; Accepted 25 December 2013; Published 6 February 2014

Academic Editor: Baozhen Yao

Copyright (c) 2014 Qingyang Xu et al. This is an open access article distributed under the Creative Commons Attribution License, which permits unrestricted use, distribution, and reproduction in any medium, provided the original work is properly cited.

\begin{abstract}
The vessel collision accidents cause a great loss of lives and property. In order to reduce the human fault and greatly improve the safety of marine traffic, collision avoidance strategy optimization is proposed to achieve this. In the paper, a multiobjective optimization algorithm NSGA-II is adopted to search for the optimal collision avoidance strategy considering the safety as well as economy elements of collision avoidance. Ship domain and Arena are used to evaluate the collision risk in the simulation. Based on the optimization, an optimal rudder angle is recommended to navigator for collision avoidance. In the simulation example, a crossing encounter situation is simulated, and the NSGA-II searches for the optimal collision avoidance operation under the Convention on the International Regulations for Preventing Collisions at Sea (COLREGS). The simulation studies exhibit the validity of the method.
\end{abstract}

\section{Introduction}

With the appearance of larger, specialized, and faster vessel, the environment of marine traffic becomes more and more sophisticated. Therefore, the collision accidents occur frequently, even though some advanced auxiliary vessel collision avoidance equipment is widely used aboard. The vessel collision accidents cause a great loss of lives and property. Navigational collision is a major safety concern at sea. According to the investigation of Li et al. [1], 80\% of collision accidents are caused by human factor, including wrong decision or careless. Therefore, the subject of how to provide reasonable navigational information for navigators has been studied.

In early navigation, vessel collision avoidance depended on the experience of navigators due to lack of advanced equipment. Recently, Automatic Radar Plotting Aid (ARPA) appears and is widely installed on most merchant vessels [2]. The data handling and graphic display of equipment enhance the collision avoidance efficiency, and the decision is more and more objective [3]. ARPA provides an interface for navigators to evaluate the validity of a collision avoidance strategy by the predicted values of two important parameters of target vessels-Distance at Closest Point of Approach (DCPA) and Time to Closest Point of Approach (TCPA) [4]. The navigator can make a decision according to result of ARPA. However, the ARPA only can assess the movement of vessels according to a certain speed and course, and it cannot evaluate the economic characteristic of the different operations. Therefore, the navigator's decision is always suboptimal, and sometimes the wrong judgment is rendered.

With the appearance and development of new navigation equipment like AIS [5, 6], advanced computer technology, and so forth, the application of intelligent optimization algorithm has been used for collision avoidance strategy searching. Genetic algorithm (GA) is a popular heuristic algorithm, which has been used for many subjects, such as system identification $[7,8]$, supply chain [9], and scheduling problem [10]. Śmierzchalski and Michalewicz [11], Szlapczynski [12], and Szlapczynski and Szlapczynska [13] first made use of genetic algorithm to plan the route of vessel in static or dynamic environment in order to avoid obstacles. Similar heuristic optimization algorithms have been used by other 
researchers: GA is used to find the optimal path and manoeuvres in collision avoidance [14-16]. Cheng and Liu made use of genetic algorithm to optimize the collision avoidance route of urban river $[17,18]$. There are also other related approaches used to vessel collision avoidance and route planning, such as ant colony algorithm [19-21] and expert system [22]. The collision avoidance optimization problem is to find a reasonable way to make the vessel avoid the obstacles with minimal wastage and maximum safety. It is a multiobjective optimization problem. The above-mentioned collision avoidance problems are generally considered to have been solved form the scientific point of view, even if some solutions have not been applied yet. Moreover, in most of above-mentioned researches, the problems are always defined as a single-objective problem or transformed to a single-objective problem by the weights allocation. However, the parameters of weight are always experiential, which are difficult to set.

Recently, the number of multiobjective evolutionary algorithms increases drastically due to their popularity and capability of successfully solving multiobjective optimization problems $[23,24]$. In this paper, we adopt a multiobjective optimization algorithm (NSGA-II) instead of a singleobjective optimization algorithm to optimize the collision avoidance strategy. The NSGA proposed by Srinivas and Deb [25] has been successfully applied to solving many problems. An improved version of NSGA, which they called NSGA-II, overcome some disadvantages of NSGA, such as high computational complexity of nondominated sorting, lack of elitism, and need a sharing parameter. NSGA-II is considered as the state-of-the-art multiobjective evolutionary algorithm $[26,27]$. The collision avoidance operation of vessel is selected as the optimized variables instead of the path that is constructed of coordinates set. Thus, the navigators can get the rudder angle for collision avoidance by the optimization of NSGA-II.

This paper is organized as follows. The problem of vessel collision avoidance optimization is presented firstly in Section 2, and then the multiobjective optimization algorithms (NSGA-II) for collision avoidance strategy optimization are discussed in Section 3. Finally, a of crossover encounter situation is simulated, and the optimization process and results are discussed in Section 4.

\section{Vessel Collision Avoidance Optimization Problems}

2.1. Multiobjective Optimization Problem. A multiobjective optimization problem is defined by a set of $D$ parameters (decision variables), a set of $N$ objective functions, and a set of $m$ constraints. The objective functions and the constraints are functions of the decision variables. The aim of the optimization is to

$$
\text { minimize (and maximize) } \quad \begin{aligned}
y & =f(x) \\
& =\left[f_{1}(x), f_{2}(x), \ldots, f_{M}\right]
\end{aligned}
$$

s.t.

$$
\begin{array}{r}
x=\left[x_{1}, x_{2}, \ldots, x_{d}, \ldots, x_{D}\right] \\
x_{d_{\min }} \leq x_{d} \leq x_{d_{\max }} \\
\quad \times(d=1,2, \ldots, D),
\end{array}
$$

where $x$ is the vector of decision variables, $f$ are the objective functions, $M$ is the objective number, and $x_{d_{-} \min }$ and $x_{d_{-} \max }$ are the bound of decision variables.

Considering a minimization problem for each objective, it is said that a decision vector $X_{a}$ dominates another vector $X_{b}\left(X_{a}>X_{b}\right)$ if and only if

$$
\forall i=1,2 \ldots k, \quad f_{i}\left(X_{a}\right) \geq f_{i}\left(X_{b}\right) \quad \text { or } \quad f_{i}\left(X_{a}\right)>f_{i}\left(X_{b}\right) .
$$

We can say that a vector of decision variables $X$ is a Pareto-optimal solution or nondominated solution. Therefore, the Pareto-optimal set is the set of all Pareto-optimal solutions. The aim of an optimization algorithm is to find a set of Pareto-optimal solutions approximating the true Paretooptimal front.

2.2. Collision Avoidance Strategy Optimization Problem. The goal of the collision avoidance strategy optimization is to find an optimal collision avoidance operation, which has the minimal time loss or way loss spending on maneuvering, while fulfilling some COLREGS rules [28]. Therefore, the individual evaluation is consolidated of security and economic factors [29]. The evaluation function includes three elements. The first part is the security assessment of the strategy, and it is a very important part of the evaluation function, namely, risk of collision. The safety of the strategy is mainly reflected by the collision risk between local vessel and target vessel. After generating the initial strategy, the Nomoto model is used to simulate the vessel and the collision risk is evaluated according to the information of the vessels. Different collision avoidance strategies lead to different collision risks. The second factor is the economic factors [12], such as the sailing time and distance. The third one is the smoothness factor, namely, the rudder angle changing or course changing.

Therefore, the collision avoidance strategy optimization based multiobjective is composed of three objectives as follows:

$$
\text { minimize } y=f(x)=\left[f_{1}, f_{2}, f_{3}\right] \text {. }
$$

The fitness can be calculated by the simulation data, and the primary optimized variable is the rudder angle that navigator or autopilot should be adopted in the collision avoidance.

2.2.1. Safety Evaluation. In the navigation, safety is the primary problem. In the paper, the minimum distance of the two vessels in the collision avoidance is adopted to evaluate the security. The evaluation function is shown as follows:

$$
f_{1}^{i}=\operatorname{safety}_{i}=F-\min \left(D^{i}\right)
$$


where safety ${ }_{i}$ is the safety evaluation of $i$ th strategy, $D$ is the distance of passing close, $F$ is a big value to make sure that the safety $y_{i}$ is positive, and function $\min ()$ is minimum function. In the process of navigation, the routing is not a line, but a track belt. According to Yang's literature [30], the distance between two vessels should be maintained more than $\left(L_{0}+L_{t}\right) \pi / 18$ to prevent vessel collision caused by suction. If the distance between the two vessels is less than $\left(L_{0}+L_{t}\right) \pi / 18$ in the simulation, the two vessels have a collision and the fitness is zero.

COLREGS rules should be considered except for $f_{1}^{i}$, which is an international rule at sea. Some rules are about the collision avoidance as follows.

(1) None of the ship domains are violated, that means every vessel having its own zone, which cannot be violated by other vessels.

(2) Speed alterations are not to be applied unless necessary (collision cannot be avoided by a configured maximum course alteration value). In vessel collision avoidance, the speed is always constant except that the collision avoidance cannot be achieved by course turning.

(3) COLREGS rules are not violated (especially rules 13 to 17$)$.

(a) Rule 13: "an overtaking vessel must keep well clear of the vessel being overtaken" in overtaking situations.

(b) Rule 14: "when two power-driven vessels are meeting head-on, both must alter course to starboard, so that they pass on the port side of the other" in head-on situations.

(c) Rule 15: "when two power-driven vessels are crossing, the vessel, which has the other on the starboard side, must give way" in crossing situations.

(d) Rule 16: "the give-way vessel must take early and substantial action to keep well clear."

(e) Rule 17: "the stand-on vessel may take action to avoid collision if it becomes clear that the giveway vessel is not taking appropriate action."

According to rules $13-17$, the local vessel and target vessel have different responsibility in different encounter situation. For example, the overtaking vessel cannot affect the navigation of overtaken vessel in overtaking situation; in head-on situation, the two vessels must adopt collision avoidance measures separately; crossing situation is a complex situation, the given-way vessel must adopt collision avoidance measures, and the stand-on vessel must stay the speed and course. The COLREGS rules can be considered as the constraints of the fitness evaluation. Although there are some constraints, we have considered it at the generation of population and do not integrate into the fitness function.

2.2.2. Economy Evaluation. Energy conservation is very important. The second part of evaluation is the economical evaluation of the strategy. Economy is mainly reflected by the time and voyage consumption. Since the speed of vessel is constant in the process of collision avoidance, there is a linear relation with the distance and time of vessels. Therefore, only voyage consumption is considered in the evaluation function. The evaluation function is as follows:

$$
f_{2}^{i}=\text { economy }_{i}=\sum_{k}^{n} \sqrt{\left(x_{k}-x_{k-1}\right)^{2}+\left(y_{k}-y_{k-1}\right)^{2}},
$$

where economy ${ }_{i}$ is the economical evaluation of $i$ th strategy, $k$ is the simulation steps, $n$ is the steps length of collision avoidance, and $(x, y)$ is the coordinate of vessel.

2.2.3. Smoothness Evaluation. The third part is the smoothness evaluation. Excessive smoothness of the routing is not conducive to realize collision avoidance or does not meet the actual manipulation habit. Conversely, an unduly large turning angle will cause a longer voyage with excessive energy and time consumption. In the paper, rudder angle changing is used to evaluate the smoothness of strategy:

$$
f_{3}^{i}=\operatorname{smooth}_{i}=\Delta \delta_{i},
$$

where smooth $_{i}$ is the smoothness evaluation of $i$ th strategy and $\delta_{i}$ is the rudder angle.

\section{Multiobjective Based Collision Avoidance Strategy Optimization}

3.1. The NSGA-II Algorithm. The NSGA-II [31] is one of the most famous multiobjective optimization algorithm. The NSGA [25] first is presented in 1994; then another improved one NSGA-II was proposed in 2002. According to Section 2, the rudder angle is the primary optimization variables. The individual is evaluated by the nondominated sorting method. The flow of the algorithm is shown as in Algorithm 1.

NSGA-II is based on Pareto solutions, measuring individual fitness according to their dominance property. The non-dominated individuals in the population are regarded as the fittest, and the dominated individuals are assigned lower fitness values, such as the steps (12)-(17) of the Algorithm 1. By this way, the number of dominated individuals will be counted as the fitness values instead of the value of objective function. To maintain the diversity in the Pareto solutions, NSGA-II introduced a measure of individual's density respect to other individuals in the objective space, such as the steps (34)-(38) of the Algorithm 1 and had an elitism mechanism and crowed comparison operator to preserve the diversity of population. In step (39) of the Algorithm 1, an arithmetic crossover and Gaussian mutation operation will be adopted. In the simulation of this paper, the crossover ratio is 1.2 , and the scale and shrink of Gaussian mutation are 0.1 and 0.5 .

\subsection{The Flow of Collision Avoidance Strategy Optimization.} The vessel collision avoidance strategy optimization is a complex system, which has many procedures. Figure 1 is the flow of collision avoidance strategy optimization. In order to evaluate the fitness of strategies, we adopt a mathematical 


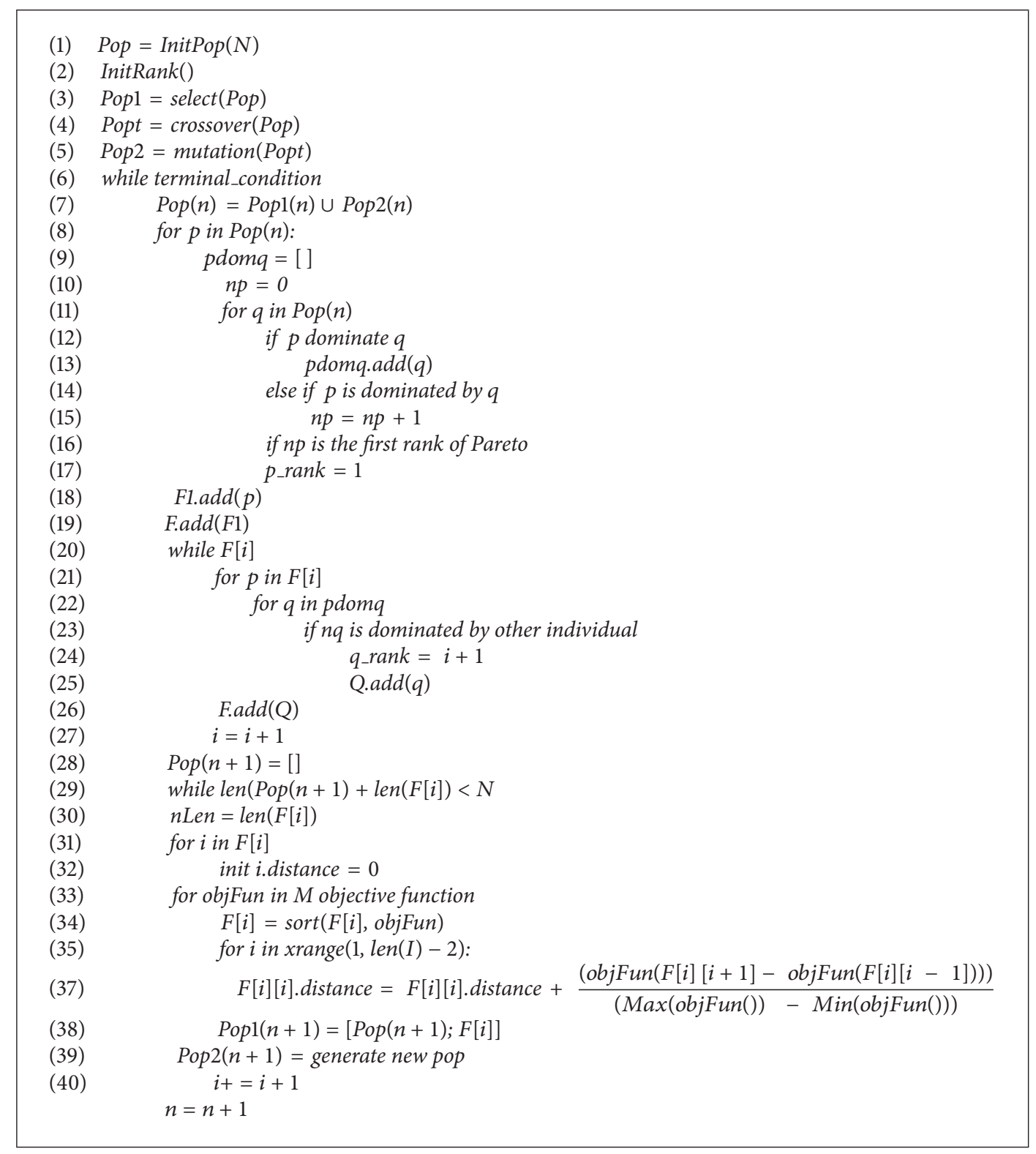

Algorithm 1

model of vessel of simulate the vessels. The vessel must assess the encounter situation all the time and collision avoidance will be carried out according to the encounter situation. The safe and economic collision avoidance strategy comes from numerous collision avoidance strategies that follows the requirement of International Regulations for Preventing Collisions at Sea (COLREGS) with highest fitness.

Collision risk evaluation is a very important part. There are many ways to evaluate the collision risk of vessels, including collision risk models [32] and ship domains [33]. In this paper, ship domain and ship Arena which are based on human praxiology and psychology are selected as the collision risk evaluation way. Fujii and Yamanouchi [34] proposed the concept of ship domain firstly. The domain is an ellipse, of which the geometrical centre is identical to the position of ship center, the major semi-axis is along the fore and aft of ship, and the minor semi-axis isalong the bear abeam of ship. Then, it is introduced to England in 1971. Goodwin [35] confirmed the existence of ship domain and established the model of ship domain according to the traffic investigation of south of the North Sea in open sea. It was derived from statistic methods from large number of record and simulator data. The definition of domain made by Goodwin [35] is "the surrounding effective waters that the navigator of a ship wants to keep clear of other ships or fixed objects." The domain is divided into three sectors. The domain is shown in Figure 2. Goodwin's model has shown that the navigator's actions is influenced by the COLREGS. The starboard side is larger than port side, and astern side is the smallest part. Different sectors of Goodwin's ship domain is not continual or convenient to carry out traffic simulation on computer. So Davis et al. [36] smoothed Goodwin's 


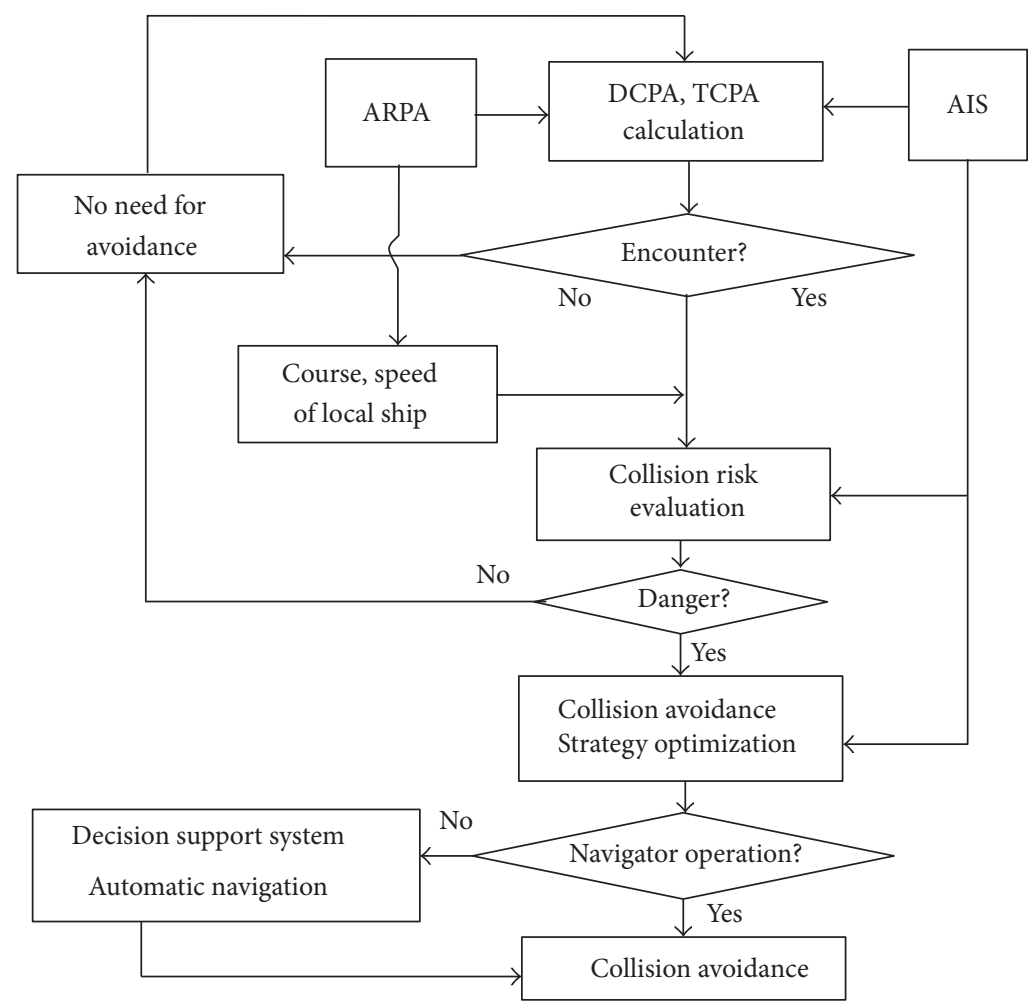

FIGURE 1: The flow of collision avoidance strategy optimization.

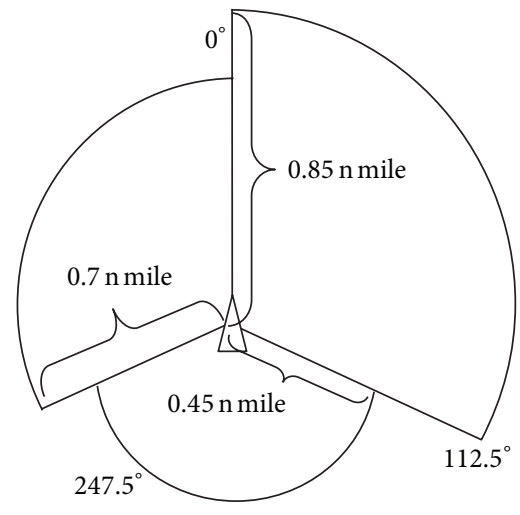

FIGURE 2: Ship domain at open sea.

domain boundary. He made use of a circle whose area is equal to the sum area of the three sectors to Goodwin's domain. The ship shifted to bottom-left corner in the Davis's ship domain to keep the characteristic of Goodwin's. It is advantage for computer simulation as in Figure 3. The numerical model is shown as follows:

$$
\begin{gathered}
F=X^{2}+Y^{2}-r^{2}, \\
X=\left(x-x_{I}\right) \cos \varphi-\left(y-y_{I}\right) \sin \varphi, \\
Y=\left(x-x_{I}\right) \sin \varphi-\left(y-y_{I}\right) \cos \varphi, \\
x_{I}=x_{R}+d \sin \left(\varphi+19^{\circ}\right),
\end{gathered}
$$

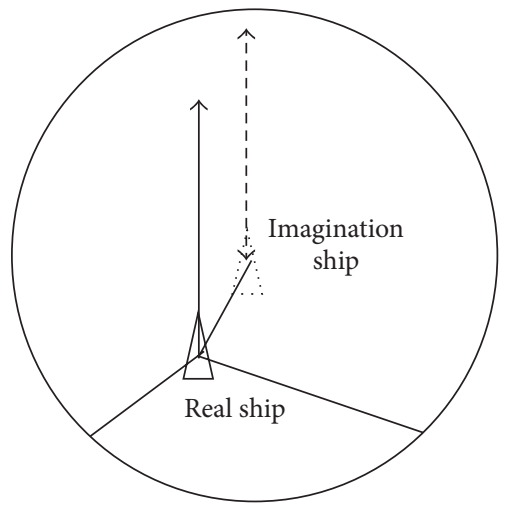

FIGURE 3: Ship domain of Davis.

$$
y_{I}=y_{R}+d \cos \left(\varphi+19^{\circ}\right) \text {, }
$$

where $F$ is the distance to domain. If the ship is outside of the domain, $F<0 . \varphi$ is the course of ship. $x_{I}, y_{I}$ are the coordination of imagination ship center. $x_{R}, y_{R}$ are the coordination of real ship center. $r$ is the radius of domain. $d$ is the distance from real ship to imagination ship.

The ship Arena is used for navigators to determine the time of taking collision avoidance actions [37]. If any, we needed to keep our own ship domain unviolated. It is a bigger area than ship domain. The parameters are shown in Figure 4.

Arena is a bigger area that navigator can adopt action or not when the target vessel is in the Arena. If the target vessel violates our domain in future, the navigator will adopt 


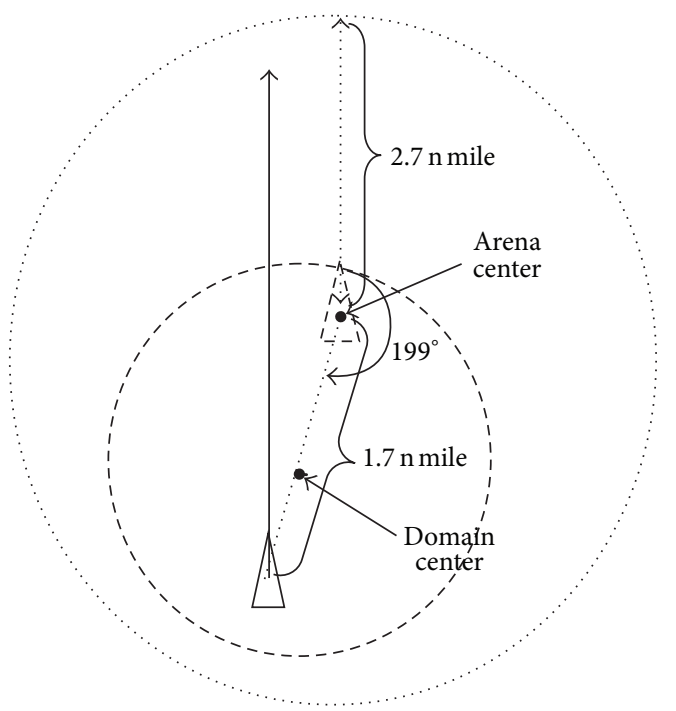

FIGURE 4: The comparison diagram of ship domain and Arena.

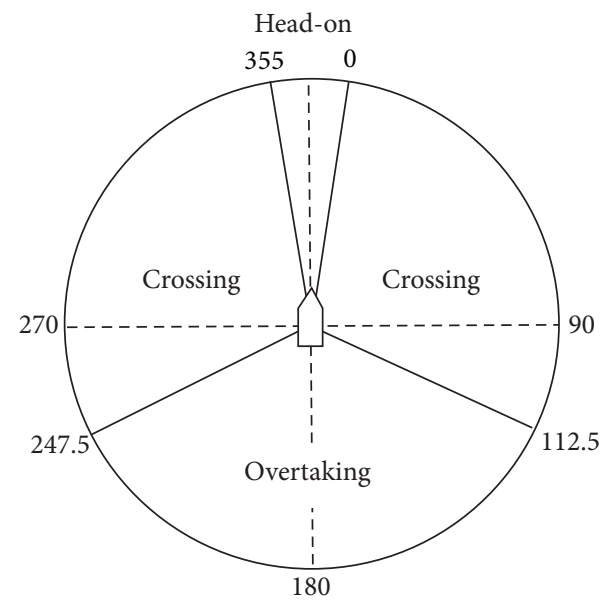

FIGURE 5: Encounter situation.

action to avoid this. In that period and in the following years or so, many scholars modified the ship domain and carried out practical researches. Since then, the ship domain has been widely used in ships' collision avoidance, marine traffic simulation, calculation of encounter rates, appraisal of collision risk, VTS design, and so forth.

\section{Simulations}

The encounter statuses of vessels are divided into head-on, crossing, and overtaking situations when two vessels have an encounter with a good visibility, the encounter statuses of vessels are divided into head-on, crossing, and overtaking situations [19]. Figure 5 is the three encounter situations. In the collision avoidance decision-making supporting system, we need to judge the encounter situation according to the status of two vessels, so as to determine the collision avoidance strategy [38].

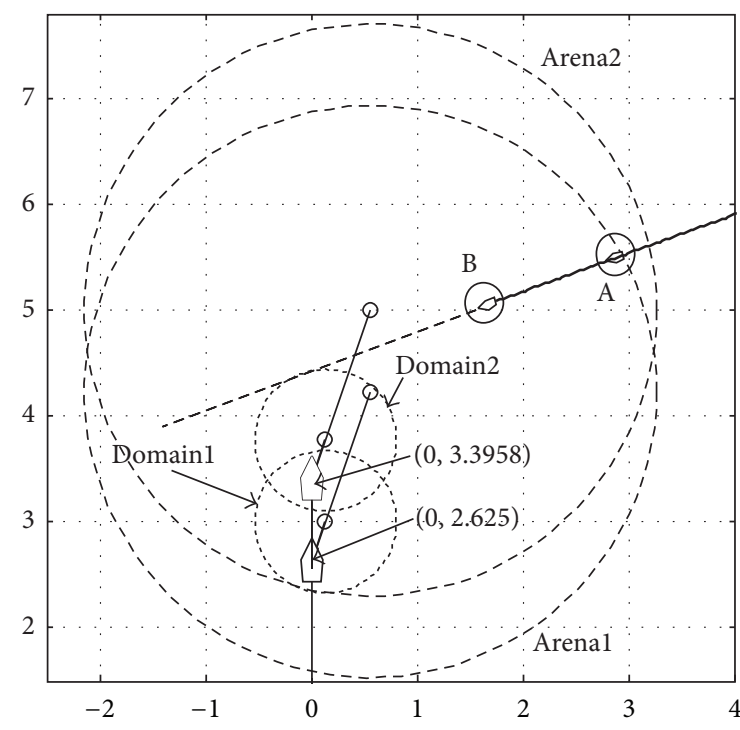

Figure 6: The encounter status of two vessels.

In the simulations, the parameters of target vessel are that the vessel moves with a speed $V_{t}=25 \mathrm{kn}$, the course is $C_{t}$ $=250^{\circ}$, the starting coordinates is $(7,5.5)$, and the length of the vessel is $110 \mathrm{~m}$. The parameters of local vessel are that the vessel moves with a speed $V_{0}=15 \mathrm{kn}$, the course is $C_{0}$ $=0^{\circ}$, the starting coordinates is $(0,0)$, the length of vessel is $250 \mathrm{~m}$, and the indexing of $K T$ are $K=0.193, T=34.119$. In the simulations, the speed of vessels is constant, and there is no wind and waves. For NSGA-II, the ratio of intermediate crossover is 1.2 and the scale and shrink of Gaussian mutatin are 0.1 and 0.5 .

According to status of two vessels, there is no collision risk at the beginning according ship Arena and domain. The two vessels will have a crossing encounter situation, and local vessel is the give-way vessel and the target vessel is standon vessel according to the collision liability division. With the navigation of the vessels, the target vessel will violate the Arena of local vessel, which is shown in Figure 6. The target vessel violates Arenal of local vessel at point $A$ but does not violate the Domainl of local vessel. Therefore, the local vessel does not need to adopt collision operation. However, the target violates the Domain 2 of local when his position is point $\mathrm{B}$, and we should adopt collision avoidance operations to avoid danger. Otherwise, the two vessels will have a collision in future, which is shown in Figure 7.

In order to reduce the evaluation amount of unnecessary individuals, the individuals are generated in the feasible region according to the COLREGS. In order to facilitate a clear description of the process of collision avoidance optimization, the population size of NSGA-II is set to 30 . In Figure 8, it is the collision avoidance effect of population of infantile iteration. In Figure 9, it is the collision avoidance effect of population of later optimization. From Figure 9 we can know that the individuals are convergent to a certain area. 


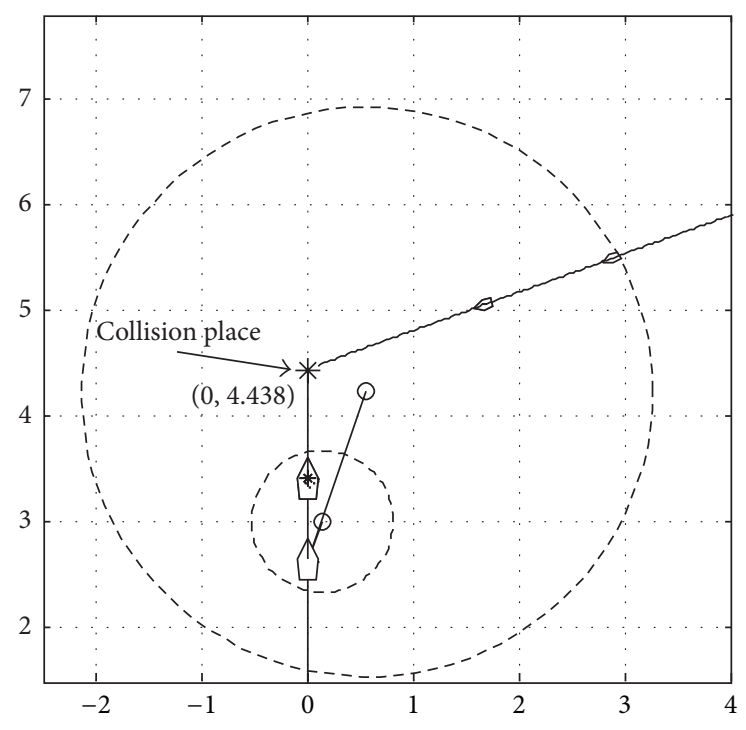

Figure 7: The two vessels have a collision.

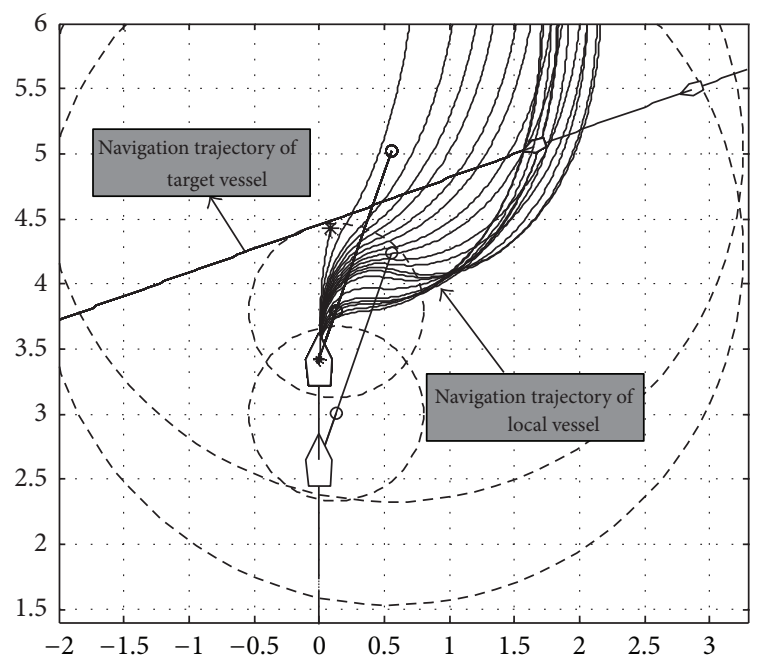

FIGURE 8: The collision avoidance effect of population of infantile iteration.

According to the final optimization result, an optimal collision avoidance strategy is selected when the rudder angle is 11 degrees, according to the fitness priority. The changes of DCPA, TCPA, and RT (distance of vessels) are shown in Figure 10. From the figure, we can see that the distance of two vessels is smaller and smaller with the navigation. If there is not collision avoidance operation, the two vessels will have collision before Time 200. The DCPA and TCPA have a jump from Time 200 when the collision avoidance operation is adopted. After collision avoidance, RT becomes bigger.

In Figure 11, it is the comparison diagram of DCPA, TCPA, and RT when rudder angle is 6,11 , and 20 degrees.

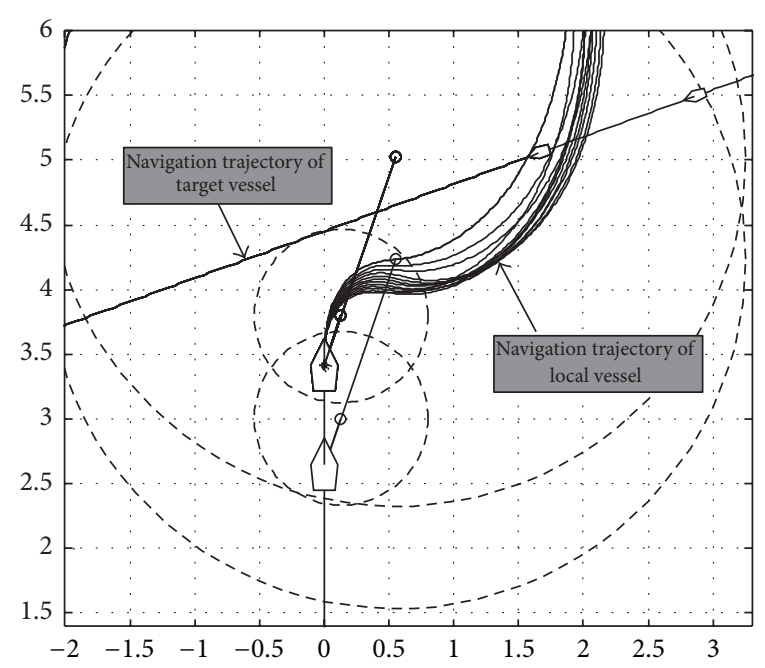

FIGURE 9: The collision avoidance effect of population of later optimization.

The DCPA change of rudder angle $=11$ is bigger than rudder angle $=6$ and smaller than rudder angle $=20$. The minimal $\mathrm{RT}$ of rudder angle $=11$ is bigger than rudder angle $=6$ and smaller than rudder angle $=20$.

From Figure 11, we can see that there is a bigger DCPA for a longer time when the rudder angle has a value of $11^{\circ}$. At about time 175, the collision avoidance is carried out, then the distance of two vessels has an inflection point at time 200 and RT becomes bigger subsequently. However, different operations have different effects. Although a bigger rudder angle, like $20^{\circ}$, can obtain well safety fitness, other fitness will be suboptimal. Therefore, we can get an optimal collision strategy ( $11^{\circ}$ of rudder angle) by the optimization of NSGA-II.

\section{Conclusions}

The environment of maritime traffic becomes more and more hostile. Therefore, the subject of how to provide reasonable collision avoidance information for navigators aboard has been studied. In this paper, we make use of the advanced navigational equipment and multiobjective optimization algorithm to obtain an optimal collision avoidance strategy. The optimization result is a safe and economical operation instruction considering COLREGS. The simulation results exhibit the validity of the method. After that the optimal collision avoidance operation is carried out, and the vessel will be out of danger. Then, the vessel can resume to the original route. Although the results are promising, we only discussed the optimization mechanisms of the collision avoidance system. The optimization is based on the navigational information of local vessel and target vessel. The corresponding sensors are required on actual vessel, and there will be a complex sea conditions in practical. 


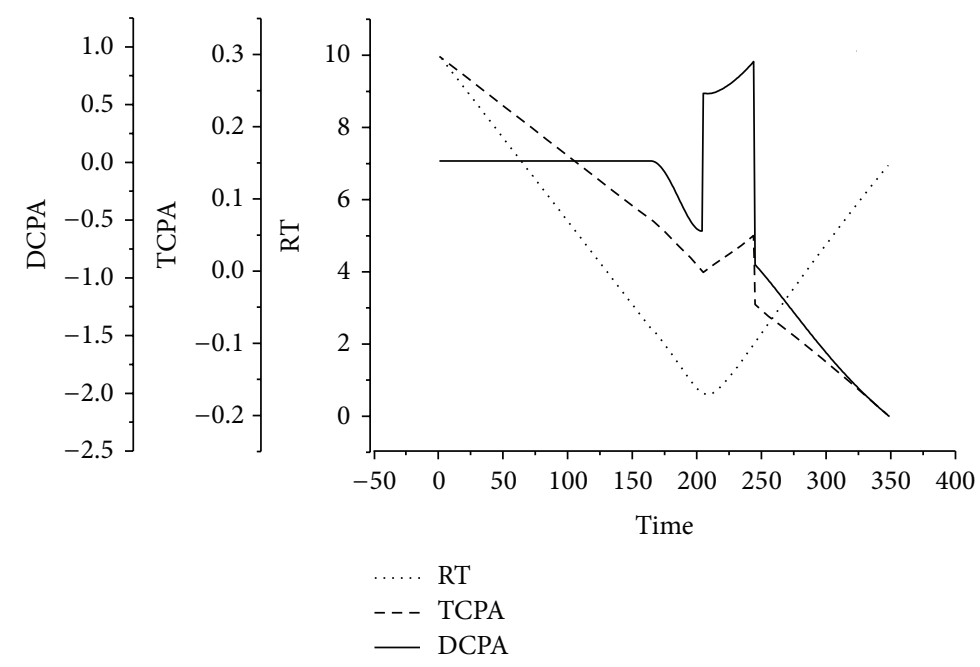

FIgURE 10: The changes of DCPA, TCPA, and RT when rudder angle is 11 degrees.

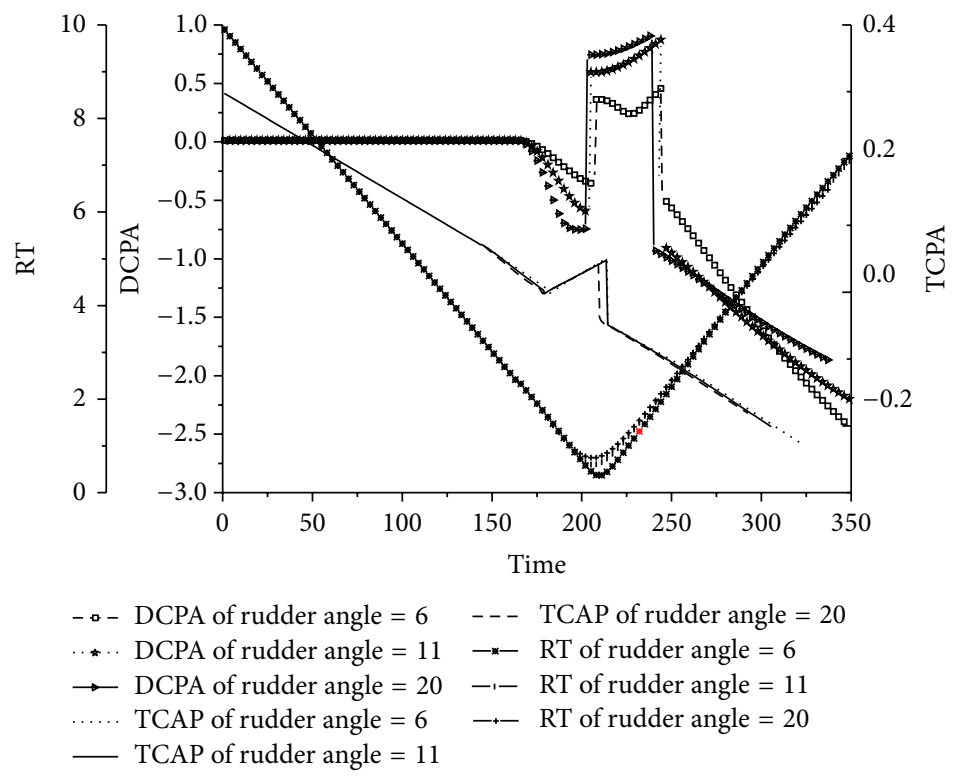

FIGURE 11: The changes of DCPA, TCPA, and RT when rudder angle is 6, 11, and 20 degree.

\section{Conflict of Interests}

The authors declare that there is no conflict of interests regarding the publication of this paper.

\section{Acknowledgments}

The author thanks the reviewers for their careful reading and helpful comments that have improved the paper. This work is supported by the National Natural Science Foundation of China (under Grant 51009017), Applied Basic Research Funds from Ministry of Transport of P. R. China (under Grant 2012-329-225-060), China Postdoctoral Science Foundation (under Grant 2012M520629), and Fundamental Research Funds for the Central Universities of China (under Grants 2009QN025, 2011JC002, and 3132013025).

\section{References}

[1] L. Li, S. Yang, B. Cao, and Z. Li, "A summary of studies on the automation of ship collision avoidance intelligence," Journal of Jimei University (Natural Science), vol. 11, no. 2, pp. 188-192, 2006.

[2] T. Statheros, G. Howells, and K. McDonald-Maier, "Autonomous ship collision avoidance navigation concepts, technologies and techniques," Journal of Navigation, vol. 61, no. 1, pp. 129-142, 2008.

[3] X. Zeng, M. Ito, and E. Shimizu, "Collision avoidance of moving obstacles for ship with genetic algorithm," in Proceedings of the 6th International Workshop on Advanced Motion Control, pp. 513-518, Nagoya, Japan, 2000.

[4] H. C. Chin and A. K. Debnath, "Modeling perceived collision risk in port water navigation," Safety Science, vol. 47, no. 10, pp. 1410-1416, 2009. 
[5] H.-Z. Hsu, N. A. Witt, J. B. Hooper, and A. P. Mcdermott, "The AIS-Assisted collision avoidance," Journal of Navigation, vol. 62, no. 4, pp. 657-670, 2009.

[6] J. M. Mou, C. van der Tak, and H. Ligteringen, "Study on collision avoidance in busy waterways by using AIS data," Ocean Engineering, vol. 37, no. 5-6, pp. 483-490, 2010.

[7] R. D. Al-Dabbagh, A. Kinsheel, M. S. Bin Baba, and S. Mekhilef, "An integration of compact Genetic algorithm and local search method for optimizing ARMA (1,1) model of likelihood estimator," in Proceedings of the 2nd International Conference on Computer Science and Computational Mathematics, pp. 60-67, Melaka, Malaysia, 2013.

[8] R. D. Al-Dabbagh, M. S. Baba, S. Mekhilef, and A. Kinsheel, "The compact Genetic Algorithm for likelihood estimator of first order moving average model," in Proceedings of the 2nd International Conference on Digital Information and Communication Technology and it's Applications, pp. 474-481, 2012.

[9] B. Yu, Z. Yang, and C. Cheng, "Optimizing the distribution of shopping centers with parallel genetic algorithm," Engineering Applications of Artificial Intelligence, vol. 20, no. 2, pp. 215-223, 2007.

[10] B. Yu, Z.-Z. Yang, and B. Yao, "An improved ant colony optimization for vehicle routing problem," European Journal of Operational Research, vol. 196, no. 1, pp. 171-176, 2009.

[11] R. Śmierzchalski and Z. Michalewicz, "Modeling of ship trajectory in collision situations by an evolutionary algorithm," IEEE Transactions on Evolutionary Computation, vol. 4, no. 3, pp. 227241, 2000.

[12] R. Szlapczynski, "Evolutionary sets of safe ship trajectories: a new approach to collision avoidance," Journal of Navigation, vol. 64, no. 1, pp. 169-181, 2011.

[13] R. Szlapczynski and J. Szlapczynska, "On evolutionary computing in multi-ship trajectory planning," Applied Intelligence, vol. 37, pp. 155-174, 2012.

[14] M. Ito, F. Zhang, and N. Yoshida, "Collision avoidance control of ship with genetic algorithm," in Proceedings of the IEEE International Conference on Control Applications and IEEE International Symposium on Computer Aided Control System Design, pp. 1791-1796, Kohala Coast, Hawaii, USA, August 1999.

[15] X. Zeng, "Evolution of the safe path for ship navigation," Applied Artificial Intelligence, vol. 17, no. 2, pp. 87-104, 2003.

[16] M.-C. Tsou, S.-L. Kao, and C.-M. Su, "Decision support from genetic algorithms for ship collision avoidance route planning and alerts," Journal of Navigation, vol. 63, no. 1, pp. 167-182, 2010.

[17] X. Cheng and Z. Liu, "Study on ship collision avoidance trajectory optimization in inland waterways with genetic algorithm," Navigation of China, vol. 67, no. 2, pp. 38-46, 2006.

[18] X. Cheng and Z. Liu, "Trajectory optimization for ship collision avoidance in three fork sea-route of inland waterway," Ship \& Ocean Engineering, vol. 37, no. 4, pp. 74-76, 2008.

[19] M.-C. Tsou and C.-K. Hsueh, "The study of ship collision avoidance route planning by ant colony algorithm," Journal of Marine Science and Technology, vol. 18, no. 5, pp. 746-756, 2010.

[20] J. B. Escario, J. F. Jimenez, and J. M. Giron-Sierra, "Optimisation of autonomous ship manoeuvres applying Ant Colony Optimisation metaheuristic," Expert Systems with Applications, vol. 39, no. 11, pp. 10120-10139, 2012.

[21] B. Yu and Z. Z. Yang, "An ant colony optimization model: the period vehicle routing problem with time windows," Transportation Research E, vol. 47, no. 2, pp. 166-181, 2011.
[22] T. Tran, Avoidance Navigation Totally Integrated System, Universtiy of Southamton, Southampton, UK, 2001.

[23] N. Belgasmi, L. B. Said, and K. Ghedira, "Greedy local improvement of SPEA2 algorithm to solve the multiobjective capacitated transshipment problem," in Learning and Intelligent Optimization, pp. 364-378, Springer, Berlin, Germany, 2011.

[24] N. Belgasmi, L. B. Saïd, and K. Ghédira, "Evolutionary multiobjective optimization of the multi-location transshipment problem," Operational Research, vol. 8, no. 2, pp. 167-183, 2008.

[25] N. Srinivas and K. Deb, "Muiltiobjective optimization using nondominated sorting in genetic algorithms," Evolutionary Computation, vol. 2, no. 3, pp. 221-248, 1994.

[26] M. R. Rani, H. Selamat, H. Zamzuri, and Z. Ibrahim, "Multiobjective optimization for PID controller tuning using the global ranking genetic algorithm," International Journal of Innovative Computing, Information and Control, vol. 8, no. 1, pp. 269-284, 2012.

[27] S. Bechikh, N. Belgasmi, L. B. Said, and K. Ghédira, "PHCNSGA-II: a novel multi-objective memetic algorithm for continuous optimization," in Proceedings of the 20th IEEE International Conference on Tools with Artificial Intelligence (ICTAI '08), pp. 180-189, November 2008.

[28] R. Szlapczynski, "Evolutionary sets of safe ship trajectories within traffic separation schemes," Journal of Navigation, vol. 66, no. 1, pp. 65-81, 2013.

[29] Y. Yavin, C. Frangos, T. Miloh, and G. Zilman, "Collision avoidance by a ship with a moving obstacle: computation of feasible command strategies," Journal of Optimization Theory and Applications, vol. 93, no. 1, pp. 53-66, 1997.

[30] S. Yang, Decision-Making Support System for Ship Anti-Collision Based on Multi-Agent, Shanghai Maritime University, Shanghai, China, 2008.

[31] K. Deb, A. Pratap, S. Agarwal, and T. Meyarivan, "A fast and elitist multiobjective genetic algorithm: NSGA-II," IEEE Transactions on Evolutionary Computation, vol. 6, no. 2, pp. 182197, 2002.

[32] Q. Y. Xu, X. Y. Meng, and N. Wang, "Intelligent evaluation system of ship management," International Journal on Marine Navigation and Safety of Sea Transportation, vol. 4, no. 4, pp. 479-482, 2010.

[33] N. Wang, X. Meng, Q. Xu, and Z. Wang, "A unified analytical framework for ship domains," Journal of Navigation, vol. 62, no. 4, pp. 643-655, 2009.

[34] Y. Fujii and H. Yamanouchi, "The distribution of collisions in Japan and methods of estimating collision damage," Journal of Navigation, vol. 26, no. 1, pp. 108-113, 1973.

[35] E. M. Goodwin, "A statistical study of ship domains," Journal of Navigation, vol. 28, no. 3, pp. 328-344, 1975.

[36] P. V. Davis, M. J. Dove, and C. J. Stockel, "A computer simulation of multi-ship encounters," Journal of Navigation, vol. 35, no. 2, pp. 347-352, 1982.

[37] P. V. Davis, M. J. Dove, and C. T. Stockel, "A computer simulation of marine traffic using domains and arenas," The Journal of Navigation, vol. 33, no. 1, pp. 215-222, 1980.

[38] Z. Zheng, Research on Automatic Decision-Making System of Vessel Collision Avoidance, Dalian Maritime University, Dalian, China, 2000 


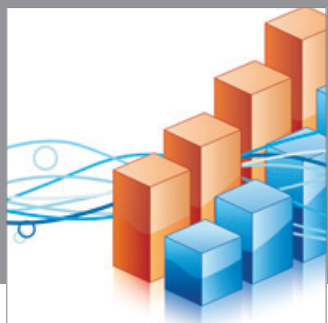

Advances in

Operations Research

mansans

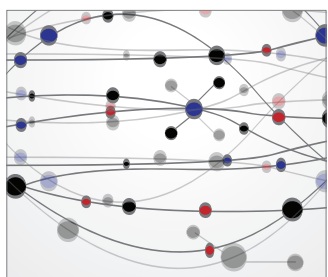

The Scientific World Journal
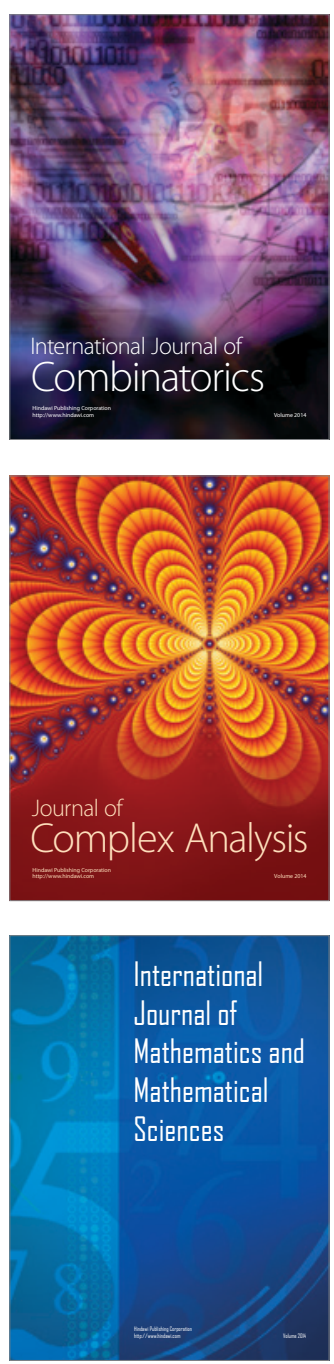
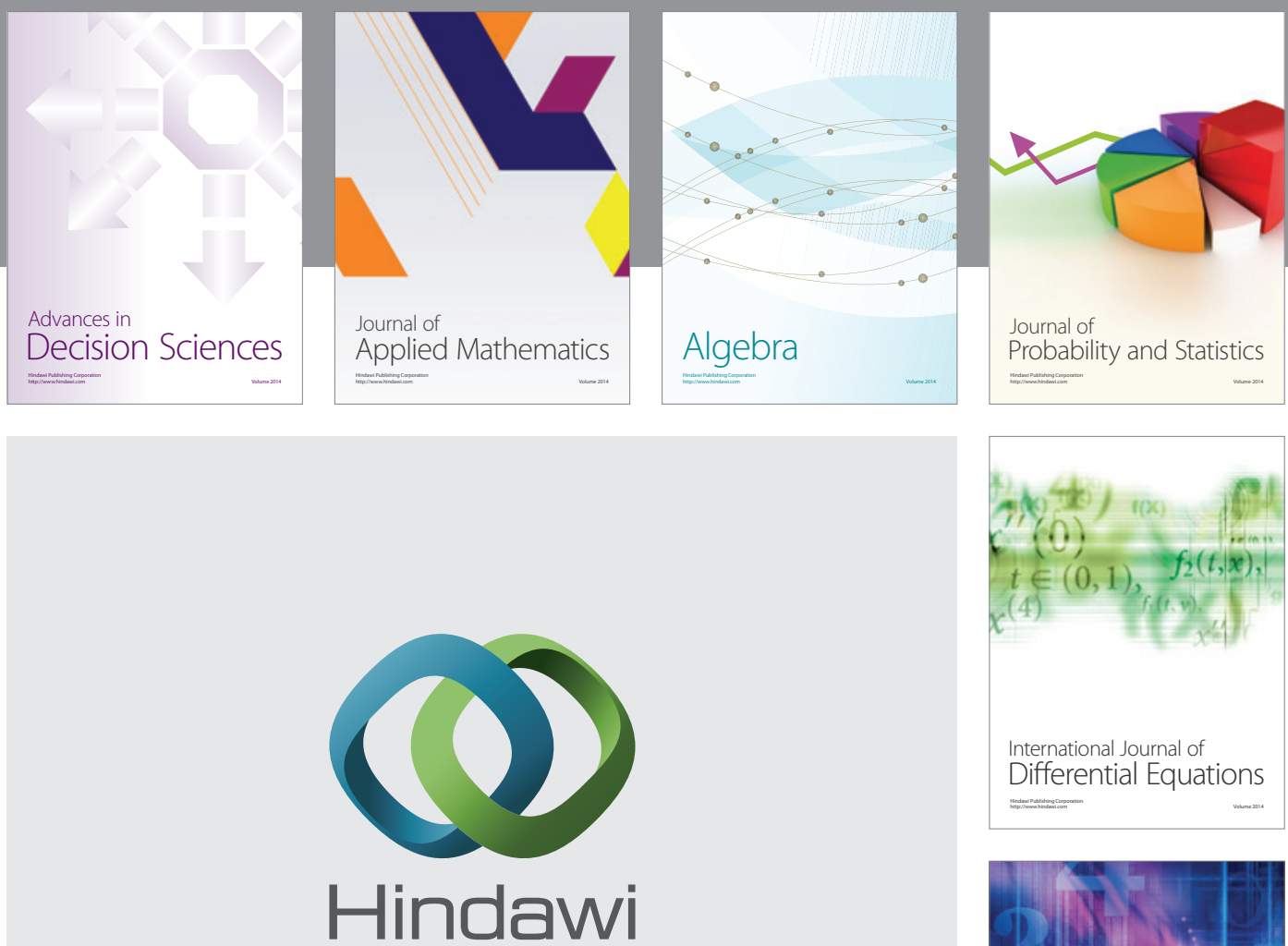

Submit your manuscripts at http://www.hindawi.com
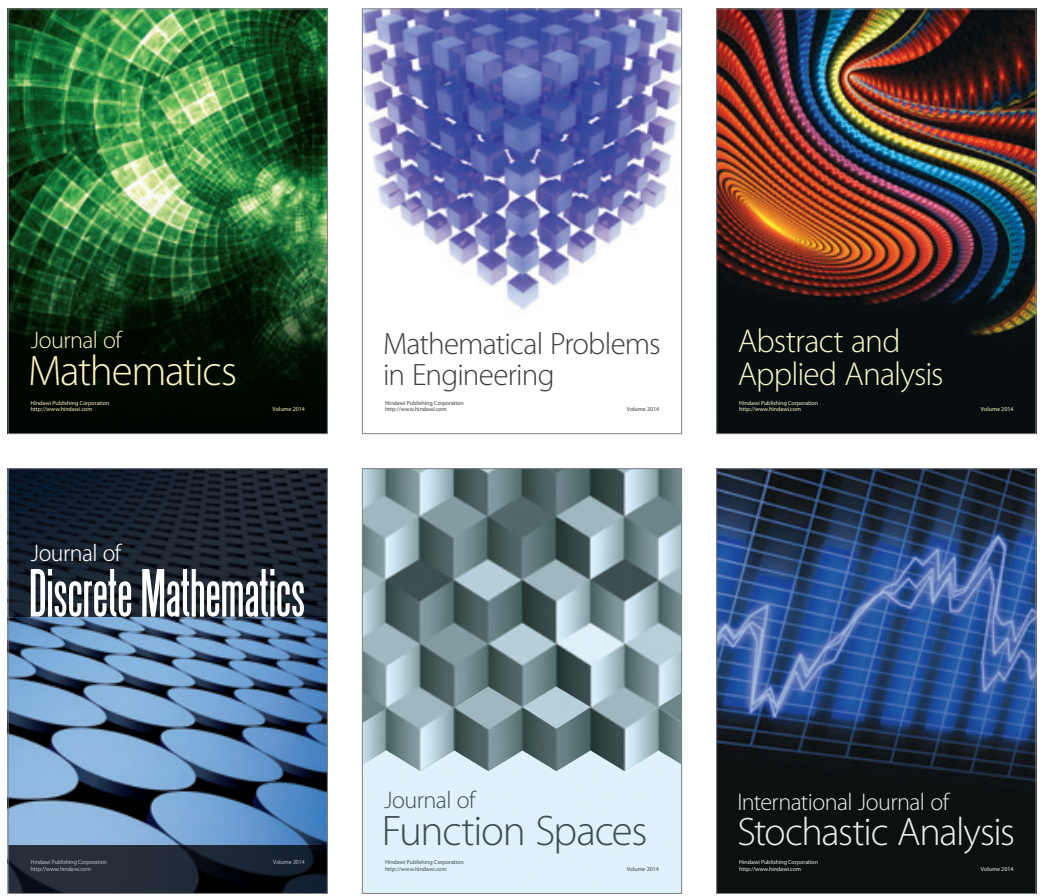

Journal of

Function Spaces

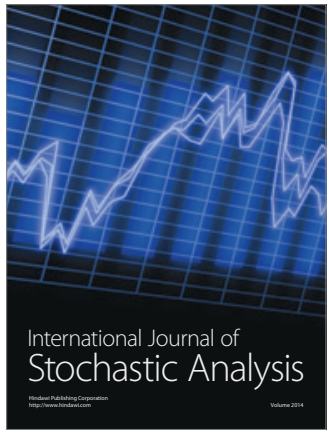

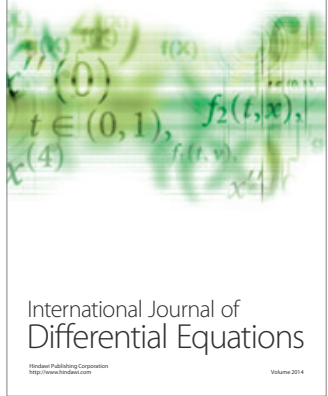
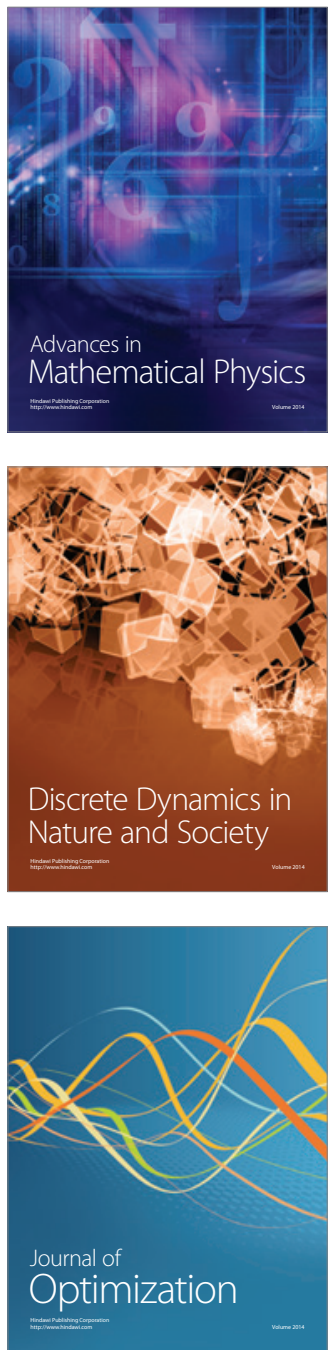